\title{
Blue-White Veil as Novel Dermatoscopic Feature in Discoid Lupus Erythematosus in 2 African-American Patients
}

\author{
Jessica Cervantes Farhaan Hafeez Mariya Miteva
}

Department of Dermatology and Cutaneous Surgery, University of Miami Miller School of Medicine, Miami, FL, USA

\section{Established Facts}

- Dermoscopic features of discoid lupus erythematosus (DLE) in dark skin include loss of pinpoint white dots, blue-gray dots in a speckled pattern, and a peripheral pigmented network.

\section{Novel Insights}

- A blue-white veil as a novel dermoscopic feature was found in 2 cases of biopsy-proven DLE in AfricanAmerican patients.

\section{Keywords}

Cutaneous lupus erythematosus · Dermatoscopy ·

Dermoscopy · Discoid lupus erythematosus .

Hyperkeratosis · Pigmented skin lesions · Skin · Trichoscopy

\begin{abstract}
Dermoscopic features of discoid lupus erythematosus (DLE) depend on the stage of the lesions: active lesions include yellow-brown dots and red dots, whereas longstanding inactive lesions show absence of follicular openings, cicatricial milky red or white patches, structureless white and brown areas, and thick arborizing vessels. Loss of pinpoint white dots, blue-gray dots in a speckled pattern, and a peripheral pigmented network have been described on dermoscopy of DLE in dark skin. We report a blue-white veil as a novel der-
\end{abstract}

\section{KARGER}

(C) 2017 S. Karger AG, Basel

E-Mail karger@karger.com

www.karger.com/sad moscopic feature in 2 cases of biopsy-proven DLE in AfricanAmerican patients. Dry trichoscopy revealed a central white area surrounded by irregular patchy areas of confluent blue and brown pigment and an overlying white "ground-glass" hue. This corresponds on pathology to the hyperkeratosis overlying interface changes at the dermal-epidermal junction, with pigment incontinence and melanophages in the papillary dermis.

(c) 2017 S. Karger AG, Basel

\section{Introduction}

Discoid lupus erythematosus (DLE) is a subtype of chronic cutaneous lupus erythematosus. The scalp is most frequently affected, but the face, trunk, and extrem- 


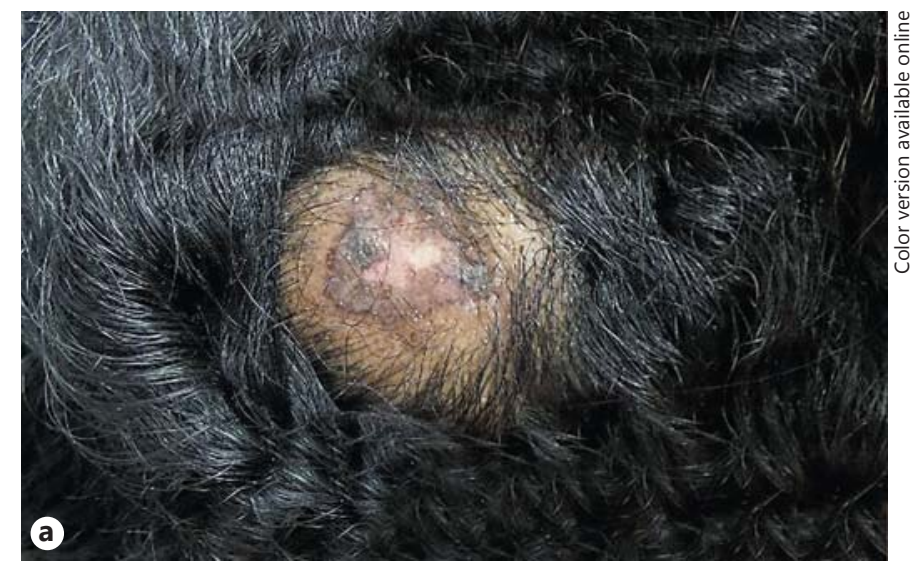

Fig. 1. Gross and trichoscopic findings. On gross examination of Case 1 (a), there is a single $1.5 \times 1.5 \mathrm{~cm}$ hyperpigmented plaque with a central white area on the parietal scalp. Trichoscopy of Case 1 (b) shows a blue-white veil (arrows), a white center (triangle), and a brown pigmented network at the periphery (star). Focal hyperkeratosis (quadrants) and thick arborizing vessels (c, diamonds) are present. The overall blurry appearance of the lesion contrasts the sharpness of the hairs. (Handyscope; FotoFinder Systems, Bad Birnbach, Germany; $\times 20$ )
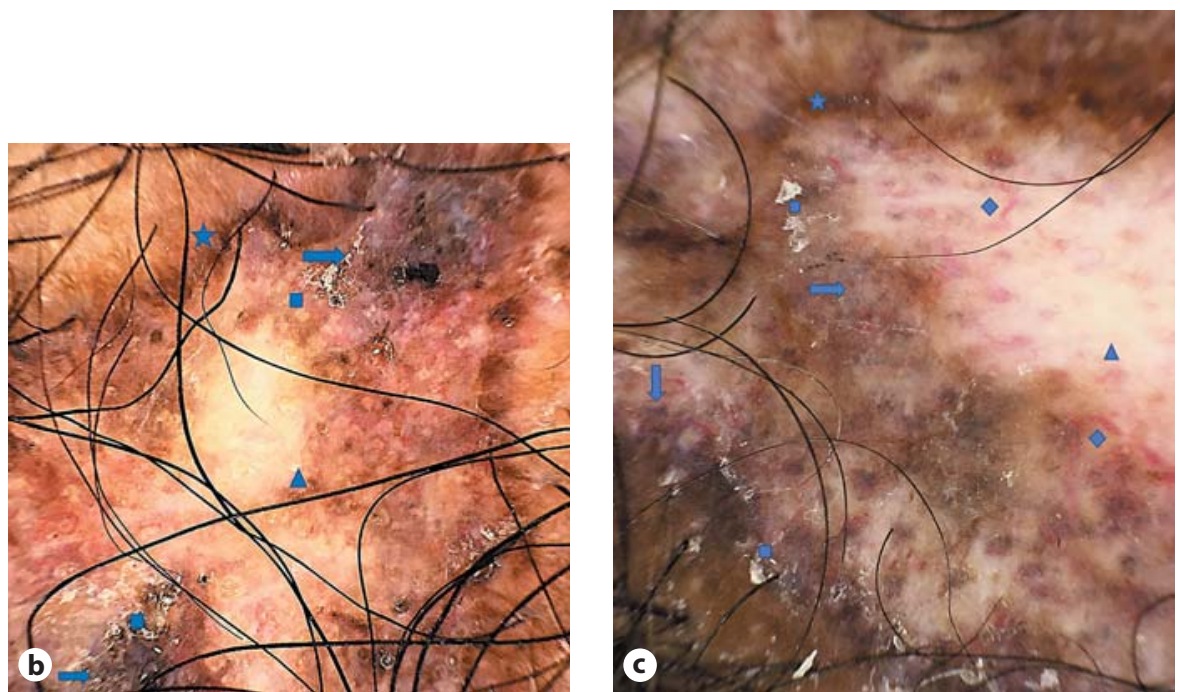

ities can also be involved. Classical lesions include violaceous to erythematosus, scaly plaques with prominent follicular plugging [1]. Without prompt diagnosis and treatment, the lesions can lead to disfiguring scarring and atrophy [2]. We report a blue-white veil as a novel dermatoscopic observation in lesions of DLE in 2 AfricanAmerican patients and stress on its pathologic correlation.

\section{Case Report}

A well-appearing, 54-year-old female and a 45-year-old male of Fitzpatrick IV and V skin type presented to the dermatology clinic with similar complaint of a growing lesion on the scalp (Fig. 1a). The lesion was tender and progressively enlarging in size during the last months. In both cases, a full-body skin examination revealed a small, single, hyperpigmented plaque on the scalp with a brown keratotic rim surrounding a hypopigmented center.
The lesions measured $1.5 \times 1.5 \mathrm{~cm}$ (Case 1) and $1 \times 1 \mathrm{~cm}$ (Case 2). Dry trichoscopy revealed a multicolor pattern consisting of a central white area surrounded by irregular patchy areas of confluent blue and brown pigment and an overlying white "ground-glass" hue (blue-white veil; Case 1). There were also thick arborizing vessels in the hypopigmented center (Case 2). A brown rim of pigmented network and focal scale was appreciated in both cases (Fig. 1b, c). Overall, the dermatoscopic appearance of the plaque was blurry in contrast to the sharp hairs in the field. Given the single existence of the lesion, the differential diagnosis included atypical melanocytic proliferation and malignant melanoma with possible regression versus a pigmented malignant keratinocytic tumor.

In both cases (Fig. 2a-c), biopsy revealed hyperkeratosis with follicular plugging in addition to an alternating attenuated and hyperplastic epidermis. There was marked vacuolar alteration of the basal layer (Fig. 2a), along with focal prominent pigment incontinence (Fig. 2b, c) and a superficial and deep periadnexal lymphohistiocytic inflammatory infiltrate (Fig. 2c). The colloidal iron stain was positive for mucin. A diagnosis of DLE was made. 

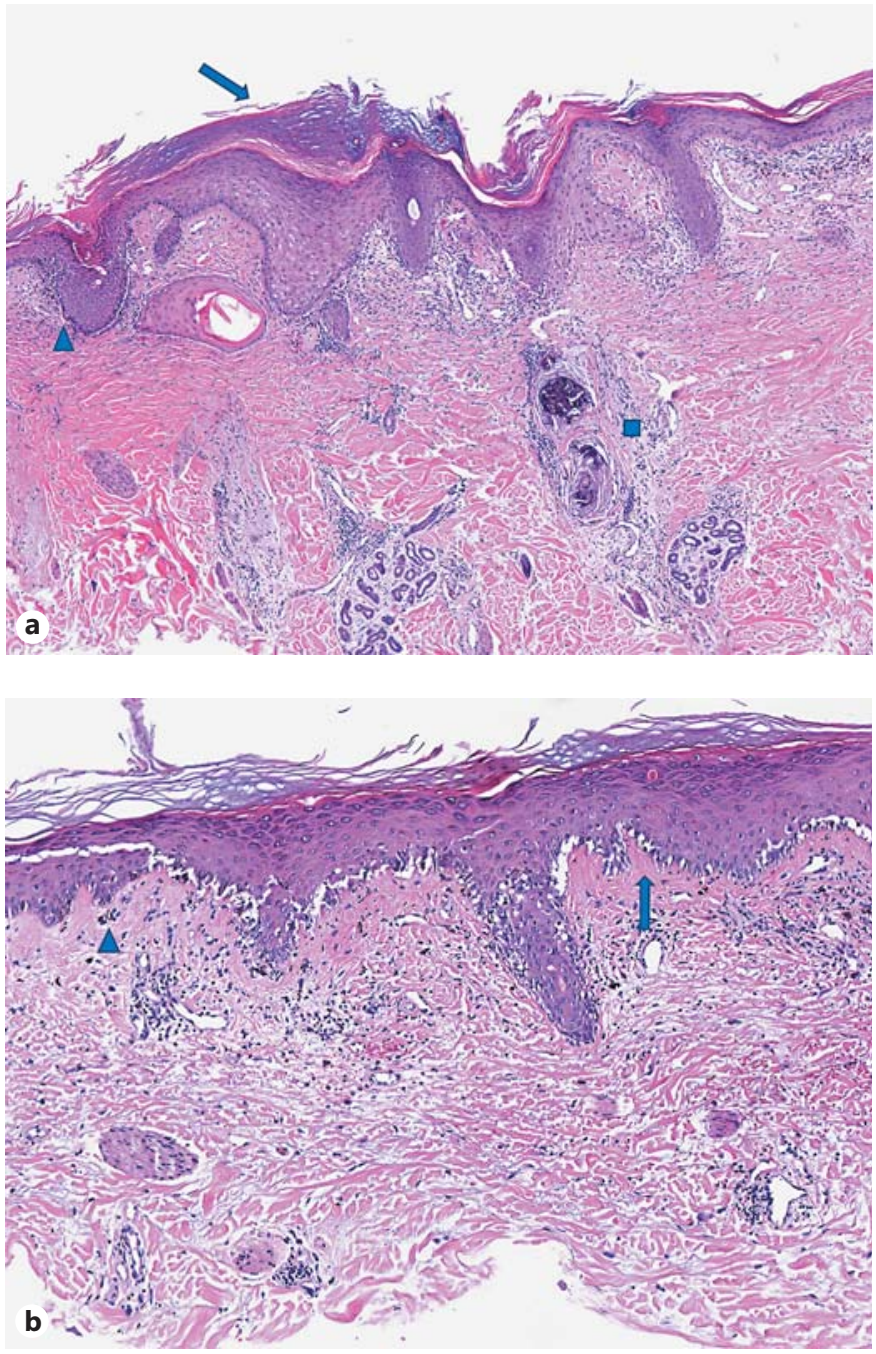

\section{Discussion}

Our cases are unusual because a single, clinically pigmented lesion showing central regression and a bluewhite veil on trichoscopy demonstrated classic DLE features on pathology. To the best of our knowledge, there are no reports of a blue-white veil associated with DLE. Several dermoscopic features have been established in DLE [3]. Active lesions show "red dots", which are erythematous, polygonal, and concentric in structure, linked to dilated vessels and extravasated erythrocytes in perifollicular distribution on pathology $[4,5]$. Large, yellowbrown dots correspond to keratotic plugs in the dilated follicular ostia $[3,2]$. Longstanding, inactive lesions show absence of follicular openings and cicatricial milky red or white patches and structureless white and brown areas [3,

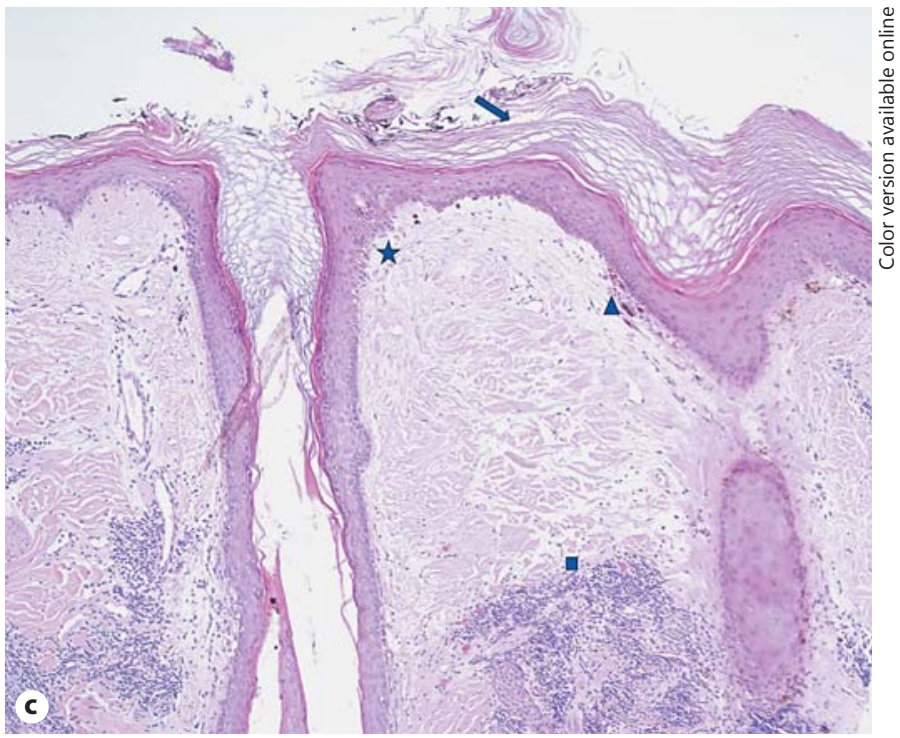

Fig. 2. Histological findings. On pathology of Case 1 (a), there is hyperkeratosis overlying focally hyperplastic epidermis (arrow). The follicular openings show keratotic plugs. There is vacuolar damage at the basement membrane (triangle) with pigment incontinence. Focal calcification is noted within fibrous streamers in the dermis (quadrant; hematoxylin and eosin. $\times 10$ ). Other portions of the specimen (b) reveal pronounced vacuolar interface changes with a thickened basement membrane (arrow) and pigment incontinence (triangle; hematoxylin and eosin. $\times 10$ ). On pathology of Case 2 (c), hyperkeratosis (arrow), interface dermatitis (star), pigment incontinence (triangle), and periadnexal lymphocytic infiltrates (quadrant) are appreciated (hematoxylin and eosin. $\times 10$ ).

$6,7]$. Thick arborizing, monstrous vessels may be noticed too $[3,5]$. Large yellow dots with thin arborizing vessels at the periphery (red spider in a yellow dot) are characteristic for the late DLE lesions [3]. In dark skin, loss of pinpoint white dots can be appreciated due to the inflammatory infiltrate involving the adnexal structures [5], and a pigmented network may be seen at the periphery of the plaque [3]. A speckled pattern of blue-gray dots has also been reported and attributed to the presence of melanophages in the interfollicular papillary dermis [5].

In dermoscopy, a blue hue is generally considered a clue to malignancy in solitary pigmented skin lesions. According to Massi et al. [8], the diagnoses most commonly associated with this finding are malignant melanoma and Spitz/Reed naevi. Histopathologically, this dermatoscopic feature correlates with the presence of an acantholytic 
epidermis with compact orthokeratosis overlying large amounts of melanin in the dermis [8]. Similar findings can be observed in the pathology of DLE lesions, such as those presented in Figure 2. The structureless, white areas described in end-stage lesions of DLE are different because they correspond histologically to diffuse dermal fibrosis [7].

We report on a novel observation that a blue-white veil can be a dermatoscopic finding of DLE without evidence of underlying melanoma. It might be more prevalent in patients of color because of the heavier load of pigment incontinence in the papillary dermis.

\section{Acknowledgement}

We are indebted to the patients for granting permission to publish this information.

\section{Statement of Ethics}

Verbal photographic and informed consent was obtained from the patients described in this article.

\section{Disclosure Statement}

The authors have no conflicts of interest to disclose.

\section{References}

1 Panjwani S: Early diagnosis and treatment of discoid lupus erythematosus. J Am Board Fam Med 2009;22:206-213.

2 Lanuti E, Miteva M, Romanelli P, Tosti A: Trichoscopy and histopathology of follicular keratotic plugs in scalp discoid lupus erythematosus. Int J Trichology 2012;4:36-38.

3 Rudnicka L, Olszewska M, Rakowska A (eds): Atlas of Trichoscopy: Dermoscopy in Hair and Scalp Disease. Springer, London, 2012.
4 Tosti A, Torres F, Misciali C, Vincenzi C, Starace $\mathrm{M}$, Miteva $\mathrm{M}$, Romanelli P: Follicular red dots: a novel dermoscopic pattern observed in scalp discoid lupus erythematosus. Arch Dermatol 2009; 145:1406-1409.

5 Miteva M, Tosti A: Hair and scalp dermatoscopy. J Am Acad Dermatol 2012;67:10401048.

6 Jha AK, Sonthalia S, Sarkar R: Dermoscopy of discoid lupus erythematosus. Indian Dermatol Online J 2016;7:458.
7 Lallas A, Apalla Z, Lefaki I, Sotiriou E, Lazaridou E, Ioannides D, Tiodorovic-Zivkovic D, Sidiropoulos T, Konstantinou D, Di Lernia V, Argenziano G, Zalaudek I: Dermoscopy of discoid lupus erythematosus. Br J Dermatol 2013;168:284-288.

8 Massi D, De Giorgi V, Carli P, Santucci M: Diagnostic significance of the blue hue in dermoscopy of melanocytic lesions: a dermoscopic-pathologic study. Am J Dermatopathol 2001;23:463-469. 